\title{
Development of a Low Cost MQL Setup for Turning Operations
}

\author{
Sumaiya Islam , Noman Khandoker, Mohamad Izham, Tengku Azizi and Sujan Debnath \\ Department of Mechanical Engineering, Faculty of Engineering and Science, Curtin University Sarawak CDT 250, 98009 Miri, Sarawak, \\ Malaysia
}

\begin{abstract}
In this study, the effect of MQL application on the tool wear, surface roughness and chip formation in turning Aluminum alloy 6061 is investigated. Experiments were carried out by plain turning of an Aluminum bar with varying depth of cut, cutting speeds (spindle speed) and cutting environments (Dry, Wet and MQL). A newly designed, cost efficient and portable MQL setup was developed for this study. For each experimental trial, five passes were carried out in order to promote the formation of tool wear. After each pass, the tool surface was examined under a microscope and the surface roughness was measured using a stylus based surface tester. The extent of tool wear from each pass is measured by using ImageJ software. Chips were collected after the five passes and were physically examined. The newly designed MQL delivery system was successful in delivering a fine mist of lubricant at the cutting point. MQL lubrication provided lower surface roughness and tool wear values compared to wet and dry conditions due to effective temperature reduction and improved lubrication penetration of cutting zones, as well as better chip flushing. Chip formed under MQL conditions had reduced chip thickness due to reduced temperatures. MQL was found to have the greatest positive impact on tool wear and surface roughness parameters based on ANOVA results.
\end{abstract}

\section{Introduction}

In manufacturing industries, machining processes such as turning is commonly used to obtain the desired size, shape, and surface of a material through the removal of material from a workpiece. During the turning operation, significant amount of heat is generated at the tool-chip interface due to friction and stresses generated from the shearing of chips. The heat generated at the cutting zone contributes to the tool wear of the cutting tool and has a negative effect on the surface roughness and surface finish. Chip formation is a machining criterion that is important in order to assess the cutting performance. In order to lower the temperatures at the cutting zone, lubricants or cutting fluids are widely used in the manufacturing industry for cooling and lubricating the tool-workpiece interface. The most common method of applying cutting fluids in turning process is by flood cooling. However, the usage of flood coolant has several harmful effects, namely environmental pollution if mishandled and high costs associated with flood machining. It is stated that "the coolants and lubricants used for machining represents $16 \%$ to $20 \%$ of the manufacturing costs" [1]. Thus, it is vital to find a way to manufacture products using more sustainable techniques, which would minimize the use of cutting fluids and promote a healthy and safe working environment. Minimum Quantity Lubrication (MQL), is an efficient cooling method that is more environmentally friendly compared to flood coolant while retaining the positive benefits of conventional cooling [2]. Aluminium alloys are commonly used in automobile and aerospace industries due to its excellent material properties, which include its high strength to weight ratio, excellent corrosion resistance and excellent thermal conductivity [3].

In this study, a newly designed cost effective MQL setup was developed for the turning operation. The effects of different process parameters (depth of cut and cutting speeds) and cutting environments (Dry, Wet and MQL) on the tool wear, surface roughness and chip formation in turning Aluminum alloy 6061 were investigated.

\section{Literature review}

Machining can be defined as a group of process of removing material from a workpiece in the form of chips using a cutting tool to obtain the desired shape, size and surface finish. According to Khan et al. [4], machinability is evaluated by cutting temperature (influences product quality and cutting tool performance), mode of chip formation, cutting forces (affects power requirements), dimensional accuracy, surface finish and tool wear and tool life. During machining with high cutting speeds and feed rates, high temperatures are generated at the cutting zone. This causes reduction in tool life by tool wear which will eventually lead to deviation of dimensional accuracy of the final product. The surface integrity is also 
affected due to tensile residual stresses, surface micro cracks and rapid oxidation present on the workpiece surface. According to Dhar et al. [5], it is stated that in machining of ductile materials, heat is generated at three regions. Firstly, heat is generated due to shear and plastic deformation at the primary deformation zone. The second region is at the chip-tool interface due to secondary deformation and sliding. The third region is at the worktool interfaces due to rubbing. These three regions create a combined effect to produce maximum temperatures at the chip-tool interface, which have an adverse effect on tool wear and surface roughness.

Tool wear is defined as the gradual failure of the cutting tool due to regular operation. Tool wear occurs due to the increase in temperature in the cutting zone during turning. There are many types of tool wear, such as flank wear, crater wear and localized wear (chipping of cutting edge). Tool wear results in the formation of an adhesive layer and a built up edge (BUE), which causes a deterioration of the quality of the workpiece surface. Theoretically, built up edge occurs on at low cutting speeds and should not be encountered on coated cutting tools, however if the coating is scratched, built up edge is formed [6]. This is shown in Sharman et al. [7] research, where during the machining of Inconel 718, it was reported that the main wear mechanism was adhesion and built up edge formation, which eventually led to removal of the tool coating. This is because the coating substrate has a higher chemical affinity to the workpiece, and with time the coating peeled off. The tungsten carbide substrate was then exposed and rapid wear of the tool was visible.

At low cutting speeds, the cutting temperatures are relatively low and abrasion wear dominates when there is only wear due to sliding friction. In these conditions, thermal softening and cutting forces are important. Built up edge can occur, and will increase the rake angle which will ease chip formation. At higher cutting speeds, built up layer (BUL) will form at the contact zone, adhesion wear will dominate and it will facilitate the sliding of the chips produced. However, in these conditions, the temperatures will be greater, and chemical diffusion between the contact pieces will facilitate the failure of the tool [8]. From List et al. [8] research on the dry machining of Aluminium alloy with cemented carbide tools, it is stated that when soft materials such as Aluminum are machined, the workpiece material adheres to the cutting tool mainly in the form of built up edge. Due to built up edge formation on the cutting tool, the geometry of the tool is changed to be more inferior with the elongation of the flank face. Inferior tool geometry leads to decreased tool machining performance as well as tool life.

During turning, the most significant type of wear which must be controlled is the flank wear. Flank wear is described as the criteria or predominant parameter in determining the tool life of a cutting tool [9]. In Paul et al. [10] study in turning AISI 1060 steel while applying cryogenic cooling, it is stated that the average auxiliary flank wear is a vital parameter to be controlled as it determines the quality of the surface finish and dimensional accuracy of the final product. Dhar et al. stated that principal flank wear $\left(\mathrm{V}_{\mathrm{B}}\right)$ is the most predominant wear as it raises cutting forces.

The surface roughness is very important as it defines the geometry of the surface to be machined and its surface texture. Surface quality is a parameter used to monitor the productivity of machine tools in producing machined components. Surface roughness is described as a vital quality indicator for machined surfaces and it has correlation to other properties such as wear resistance, fatigue strength, coefficient of friction, lubrication, wear rate and corrosion resistance of machined parts.

MQL provides reduction in tool wear and surface roughness when applied with the right conditions. Dhar et al. [5] used MQL machining technique in turning AISI 4340 steel with uncoated carbide tool. Under the same process parameters with dry and wet turning, MQL caused a significant reduction in tool wear. The reason for the reduction in tool wear was due to the reduction in flank wear (VB), which can be attributed to the reduction in flank temperature by MQL. MQL reduced the abrasive wear by retaining the tool hardness, while also reducing other temperature sensitive wear types such as adhesion and diffusion wear. Due to the reduced average auxiliary flank wear and notch wear on auxiliary cutting edge, surface roughness was also lowered when machining with MQL. The lower surface roughness with MQL was due to better control of auxiliary cutting edge deformation by abrasion, chipping and built up edge formation. Dry machining displayed higher surface roughness due to higher temperatures and stresses at tool tip.

The form, thickness and shape of chips produced when machining ductile materials depend upon the mechanical properties of the work material, the tool geometry, the cutting parameters, chip-tool interaction and cutting environment. Hence, a lot of information regarding the machining performance can be obtained from visually examining the chips formed. Machining with MQL condition is able to produce favorable chip formation by reducing chip-tool temperatures. Khan et al. [4] studied the effect of MQL on the surface roughness, tool wear and chip formation during turning AISI 9310 low alloy steel by SNMG carbide insert. In their research, it was found that the chip reduction coefficient is one of the most important machining index. Chip reduction coefficient can be defined as the degree of chip thickening and is influenced by all the machining parameters. From these results, it was found that the values of chip reduction coefficient were reduced for MQL conditions compared to dry and wet conditions. He attributed this to reduced temperatures generated at the chip tool interface, retained tool geometry from MQL application and lower built up edge formation with higher cutting speeds.

A review of various machining characteristics during turning was carried out. From the review, it is found that machinability is evaluated by cutting temperature, chip formation, cutting forces, dimensional accuracy, surface finish and tool wear. Hence, in this investigation, the three machinability criteria, tool wear, surface roughness and chip formation, will be studied in turning. Besides that, a review on the comparison of different lubrication 
modes in turning and its effect on machinability indicated that MQL provides positive machinability characteristics, such as reduced tool wear and reduced surface roughness and more favourable chip formation, when compared to dry and wet machining. MQL is also less of an environmental hazard compared to flood coolant, due to the reduced amount of lubricant used.

Aluminum alloys are widely used in manufacturing industries due to its excellent material properties. However, Aluminum alloys are difficult to machine, due to its high ductility and low melting point, which creates problems due to its affinity for bonding of work material on the cutting edges of the tool in the form of built up edge. Formation of built up edge on tool edges causes increased tool wear and eventually higher measured surface roughness values of workpiece during machining [3]. Thus, it is essential to study the effects of MQL machining with Aluminum alloys.

\section{3 methodology}

In this study, the MQL setup was designed to be costeffective, portable and able to function well on both turning and milling machines. The MQL system had to be designed and developed before the experiment could be carried out. The developed MQL setup is shown in the Figure 1.

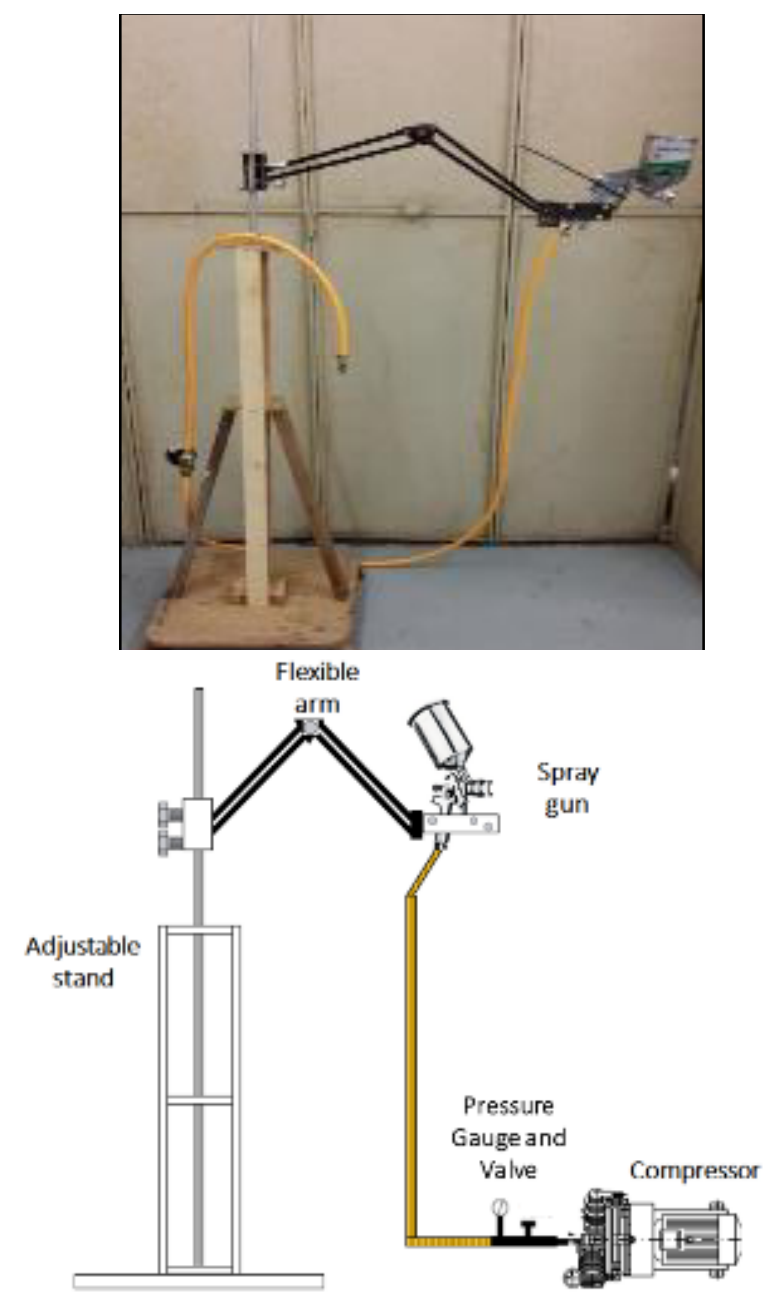

Figure 1. Developed MQL setup.
The main principle of this design is the usage of a paint spray gun, which is able to provide a fine mist of oil-air mixture easily. The spray gun used in this study is the Wynn Spray Gun WF75G, which is gravity feed spray gun. The advantage of using gravity feed gun compared to a conventional spray gun is that less pressure is required for it to operate. This provides other benefits, such as less overspray which means less amount of lubricant consumed from spraying, less wastage and a greater control of the spray. This type of spray gun also provides the option of fine tuning the spray in order to obtain a consistent spray.

The spray gun is connected to the compressor via a high pressure hose. A stand was designed to support the spray gun. The spray gun is sandwiched between two steel plates, and is clamped by tightening the bolts. The two steel plates are connected to a flexible arm, which allows for three axis movement. The flexible arm is connected to the main stand, which is also adjustable by tightening the bolts. The main stand is supported by wooden supports, to prevent the cylindrical Aluminum rod in the centre from swaying side to side. Schematic diagram of the setup is shown below

Based on the cost analysis of the design, the total cost for the materials and items purchased for the MQL setup is RM 130.21. This cost is considered low compared to the cost of a setup which would include the usage of a pump and several pressure gauges and valves, as reviewed in the literature. Hence, the MQL design is cost effective, portable (due to the ease of assembly and disassembly) and also easy to develop as the items used were readily available from the hardware shops.

The experiment was carried out by plain turning an Aluminium bar on a lathe at two different depth of cuts and three different cutting speeds under dry, wet and MQL machining environment. This was performed to study the effect of varying conditions on the machinability characteristics of the workpiece in regards to tool wear, surface roughness and chip formation. The experimental conditions are shown below in Table 1.

Table 1. Experimental Conditions.

\begin{tabular}{|c|c|c|c|}
\hline \multicolumn{4}{|c|}{ Experimental Conditions } \\
\hline $\begin{array}{l}\text { Machine } \\
\text { tool }\end{array}$ & \multicolumn{3}{|c|}{ Lathe Machine (Dalian Universal Lathe) } \\
\hline \multirow{3}{*}{$\begin{array}{l}\text { Work } \\
\text { specimen }\end{array}$} & Material & \multicolumn{2}{|c|}{ Aluminium Alloy 6061} \\
\hline & Diameter & \multicolumn{2}{|c|}{$50.9 \mathrm{~mm}$} \\
\hline & Length & \multicolumn{2}{|c|}{$200 \mathrm{~mm}$} \\
\hline \multirow{3}{*}{$\begin{array}{l}\text { Cutting } \\
\text { Tool }\end{array}$} & $\begin{array}{l}\text { Manufact } \\
\text { urer }\end{array}$ & \multicolumn{2}{|c|}{ Kyocera Tooling Japan Co. } \\
\hline & Material & \multicolumn{2}{|c|}{$\begin{array}{l}\text { CVD Titanium coated } \\
\text { carbide insert }\end{array}$} \\
\hline & Model & \multicolumn{2}{|c|}{ TJR01856 } \\
\hline \multirow{4}{*}{$\begin{array}{l}\text { Process } \\
\text { paramete } \\
\text { rs }\end{array}$} & \multicolumn{2}{|c|}{$\begin{array}{l}\text { Cutting Speed } \\
\text { (Spindle } \\
\text { Speed), } n\end{array}$} & $\begin{array}{l}700 \mathrm{rpm}, 420 \mathrm{rpm} \text { and } \\
300 \mathrm{rpm}\end{array}$ \\
\hline & \multicolumn{2}{|c|}{ Feed rate, So } & $\begin{array}{l}0.15 \mathrm{~mm} / \mathrm{rev} \\
\text { (constant) }\end{array}$ \\
\hline & \multicolumn{2}{|c|}{ Depth of cut, $t$} & $1.0 \mathrm{~mm}$ and $1.5 \mathrm{~mm}$ \\
\hline & \multicolumn{2}{|l|}{ Cutting } & $140 \mathrm{~mm}$ \\
\hline
\end{tabular}




\begin{tabular}{|l|l|l|}
\hline & \multicolumn{2}{|l|}{ Length } \\
\hline $\begin{array}{l}\text { Environm } \\
\text { ent }\end{array}$ & \multicolumn{2}{|l|}{ Dry, Wet and MQL } \\
\hline \multirow{3}{*}{$\begin{array}{l}\text { MQL } \\
\text { Supply }\end{array}$} & $\begin{array}{l}\text { Air } \\
\text { pressure }\end{array}$ & 3 bar \\
\cline { 2 - 3 } & Lubricant & $\begin{array}{l}\text { Micro-emulsion cutting } \\
\text { fluid (Yushiro MIC2500) }\end{array}$ \\
\cline { 2 - 3 } & Flow rate & $100 \mathrm{ml} / \mathrm{hr}$ \\
\hline
\end{tabular}

A Leica DM 2500M light microscope was used to capture images of the tool cutting edge. The magnification was set to a default $5 x$. The tool wear images captured were the flank face, the rake face and the auxiliary flank face. Once the image is captured and a scale has been burned on to the image, the extent/length of the tool wear can be measured using Image J software. The tool wear image was captured after each pass in order to study the wear growth/development. Colour images of the tool surface after each experiment was completed was taken using the Nikon Eclipse LV100 POL microscope. A stylus type surface tester (Surfcom SJ- 310), manufactured by Mitutoyo was used to measure the average surface roughness of the work piece. The stylus has a diamond tip with a $90^{\circ}$ cone angle and a $4 \mu \mathrm{m}$ tip radius. Each work piece was measured 3 times at three locations along the workpiece.

The chip thickness was measured using an electronic digital slide callipers manufactured by SENATOR. The digital callipers has a measuring range of $150 \mathrm{~mm} / 6$ ", a resolution of $0.01 \mathrm{~mm} / 0.0005^{\prime \prime}$ and an accuracy of $+/$ $0.03 \mathrm{~mm}$. The chips were collected after each experiment and put into containers, where they are labelled for easy identification. Chip thickness were measured for each experiment, in order to obtain the chip reduction coefficient, $\zeta$ (ratio of chip thickness and depth of cut), which is an important index of machinability.

ANOVA procedure was used to determine the process parameters that were statistically significant. The purpose of ANOVA analysis is to investigate which factors affect the experiment data significantly. This technique will be used to quantitatively estimate the relative contribution, which each controlled parameter makes to the overall measured response and expressing it as a percentage.

\section{Results and discussion}

Under MQL condition, the chip reduction coefficient (Figure 1 and 2) is significantly lower compared to the dry and wet conditions, when the cutting speed is increased. Thus, the chips produced in dry and wet condition were thicker compared to MQL condition for all experiments. This is because with MQL, there is a reduction of friction and cutting temperature generated at the cutting zone due to the MQL lubrication and cooling effect, which reduced deterioration of the effective rake angle due to built-up edge formation and wear at cutting edges. This is consistent with Khan et al. [4] study and it was added that the chip reduction coefficient decreases with an increase in cutting speed due to plasticization and shrinkage of the shear zone. At higher cutting speed, there is too much softening of the chip material due to the increased temperature and as a result the chip sliding speed is increased.

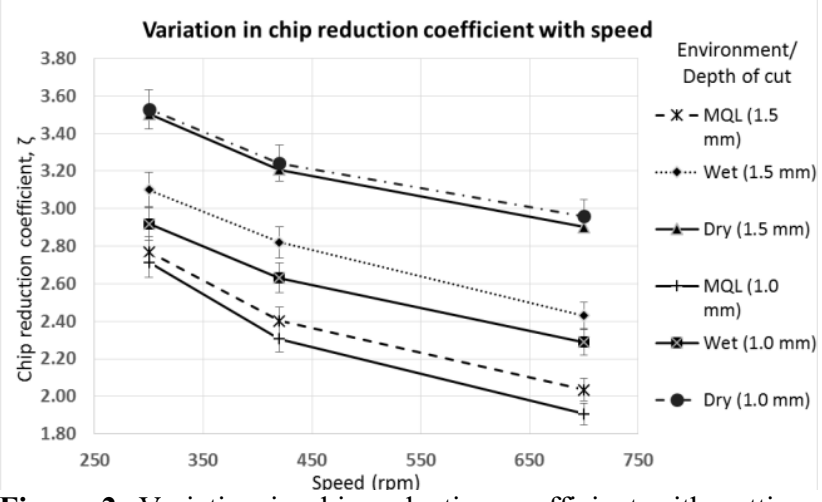

Figure 2. Variation in chip reduction coefficient with cutting speed.

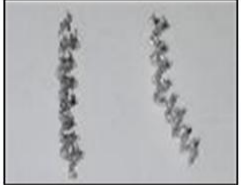

a) MOL

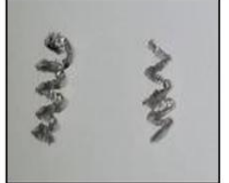

b) Dry

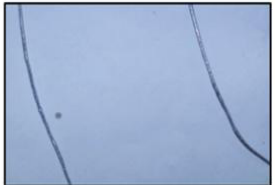

c) Wet
Figure 3. Chips produced under MQL, Dry and Wet under same parameters.

From the experimental findings, it is observed that increased cutting speed led to an increase in average principal and auxiliary flank wear for all cutting environments (Figure 3). As the machining speed is increased, quantity of work material adhered to the tool also increases. Besides that, the adhesion between the tool and chip also increased due to thermal softening of the chip with increased cutting speeds. Hence, increased material and chip adhesion over the tool rake, flank and clearance surfaces will lead to an increase likelihood of the tool material to break off when the chip deforms, causing the tool wear to increase with higher cutting speeds [11]. In addition, increased cutting speeds affect coated cutting tools by weakening the cutting edges as the crater wear is increased. This is the result of lower adhesion strength of the coating with the substrate at higher speeds. Thus, tool wear phenomenon is elevated by increasing speeds.

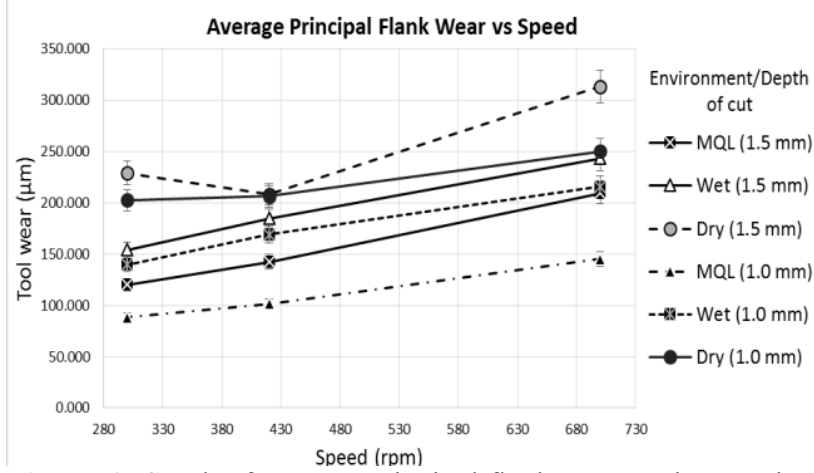

Figure 4. Graph of average principal flank wear against cutting speed.

An increase in depth of cut led to an increase in tool flank wear, based on the plot in Figure 3 and 4. This is 
because by increasing the depth of cut, cutting forces are also raised and this results in an increase in mechanical and thermal stresses on the flank area of the tool. This is also aggravated by the increase in tool contact length between the cutting edge and workpiece which results in higher amount of friction generated between the tool and workpiece. Thus, the flank wear area is extended and this leads to an increase in the flank wear width [12]. The observation that higher depths of cut increases tool flank wear is consistent with Phafat et al. [13] research and he added that at larger depths of cut, the heat and forces generated are larger and this results in an increase amount of adhered workpiece material onto the tool flank face, which accelerates the tool wear.

The flank wear values can be seen to be generally lower for MQL compared to dry and wet conditions from the plot in Figure 4. The reason for the reduction of flank wear observed under MQL condition could be due to the decreased flank temperature with MQL machining, which aid in reducing the abrasion wear by maintaining the tool hardness and also in reducing the adhesion and diffusion wear modes. The reduction in flank wear values under MQL is also reported by Hadad et al. [14] and he provided the theory that MQL reduces cutting forces which facilitates improved chip-tool interaction and maintains the cutting edge integrity. The oil droplets from the MQL reduced the friction at the sliding region as there is thinner clad material on the tool. As a result, MQL provides superior cutting performance due to the penetration of coolant/lubricant in the cutting area.

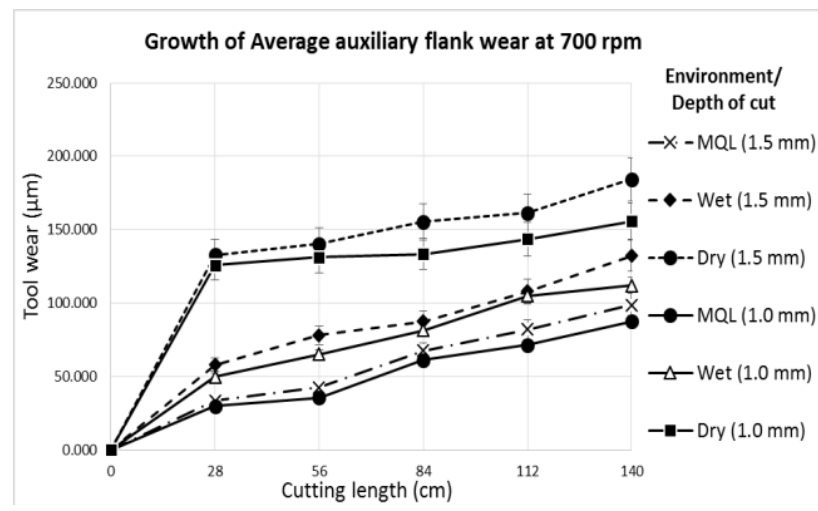

Figure 5. Graph of growth of average auxiliary flank wear at $700 \mathrm{rpm}$.

In addition, MQL condition also provided lower average auxiliary flank wear values compared to dry and wet condition based on the graph in Figure 5. Under MQL conditions, less abrasive wear, chipping and built up edge formation can be observed from the tool auxiliary flank face. The reduced auxiliary flank wear under MQL conditions is as a result of the high pressure jet of MQL behaving similar to a chip breaker and this improves the chip flushing at chip-tool-workpiece area, which provides the benefit of less work material adhered on the tool and less chip contact on the tool surfaces.

Referring to graph of surface roughness against cutting speed (Figure 5), it is observed that for MQL and wet condition, the surface roughness values decreased with increased cutting speeds. This is due to the elimination of built up edge (BUE) and reduced material adhered on tool surface at high speed machining and also the effect of MQL acting as a chip breaker. The increase in cutting speed led to the decreased formation of built up edge as there is increased heat generated at higher speeds, which causes the BUE to break off, making the cutting edge sharp again, thus leading to lower surface roughness values. This is comparable to Yoshimura et al. [15] findings, and he theorized that the surface roughness improved when the amount of adhesion decreased, as the repeated formation and breaking of adhered metal degraded the surface of the workpiece at higher speeds. For Aluminum alloys, the amount of adhered material is reduced as cutting speed is increased.

There also appears to be relationship between the tool flank wear and the surface roughness values. Based on the results, it is observed that flank wear increased with increasing cutting speeds and increased cutting speeds led to a decreased surface roughness for MQL condition. This is consistent with Shahabi et al. [16] findings and he mentioned that flank wear is the predominant wear type at the initial stages of tool wear, however at the second stage; other types of wear such as crater wear, nose wear and notch wear have a greater influence on surface roughness.

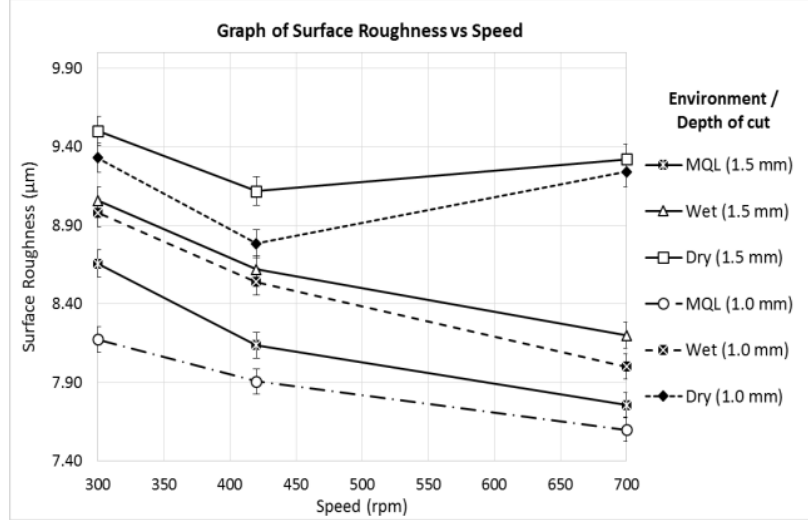

Figure 6. Graph of surface roughness against cutting speed.

In contrast, under dry conditions, the surface roughness (Figure 5) did not show a noticeable trend with cutting speeds. However, the surface roughness appeared to be highest at lower cutting speeds (300 rpm), which is a similar observation for MQL conditions. This could be attributed to the type of chip produced during the machining operation, as it has a significant effect on the surface finish. At lower cutting speeds, chip thickness is increased due to the altered shear plane angle, which results in increased cutting forces and vibration that have a detrimental effect on surface finish. As a result, increased surface roughness is obtained at lower speeds. At $700 \mathrm{rpm}$ under dry condition, the surface roughness value appeared to be higher compared to $420 \mathrm{rpm}$. This could be an effect of the increased material adhered on the workpiece surface at higher cutting speeds. At high speeds, chip adhered on the tool would have continuously scraped and ploughed the workpiece. When the adhered material becomes unstable, it will detach from the tool and adhere on the workpiece, which would increase the surface roughness of the workpiece [17]. 
For all cutting environments, an increase in depth of cut led to higher surface roughness values (Figure 6). This can be explained by the effect of increased tool wear towards surface roughness parameter. At higher depth of cut, the tool wear at both flank faces are increased, as there is an increased in the tool-workpiece contact length and tool-chip interaction. This results in increased friction generated and more material from both the tool and chips to be adhered to the workpiece surface, causing a detrimental impact on the surface roughness values. Increased depth of cut also reduced the lubrication penetration efficiency of MQL to the cutting zone due to increased plastic flow at the tool-chip contact region which contributed to higher surface roughness values.

Values of surface roughness appear to be lower for MQL condition compared to dry and wet conditions. This is due to the reduced principal flank wear with MQL, which caused the auxiliary flank wear to decrease as well. The auxiliary flank wear has a major influence on the surface finish and dimensional accuracy of the machined surface. Thus, reduced auxiliary flank wears result in reduced surface roughness values. Another factor could be due the high velocity jet of MQL forced cutting fluid particles to penetrate the tool-chip interface, resulting in reduced friction. The micro-channels present on the tool chip interface during machining serves as capillaries and through capillary action, cutting fluid can enter the cutting zone. As the MQL used is water soluble and contains a higher ratio of water to oil, heat generated through machining is evaporated. Evaporation is a more efficient mode of heat transfer compared to conduction and this contributes to lower temperatures at the chip tool interface and retained sharpness of tool cutting edge. As a result, the surface roughness is improved [18].

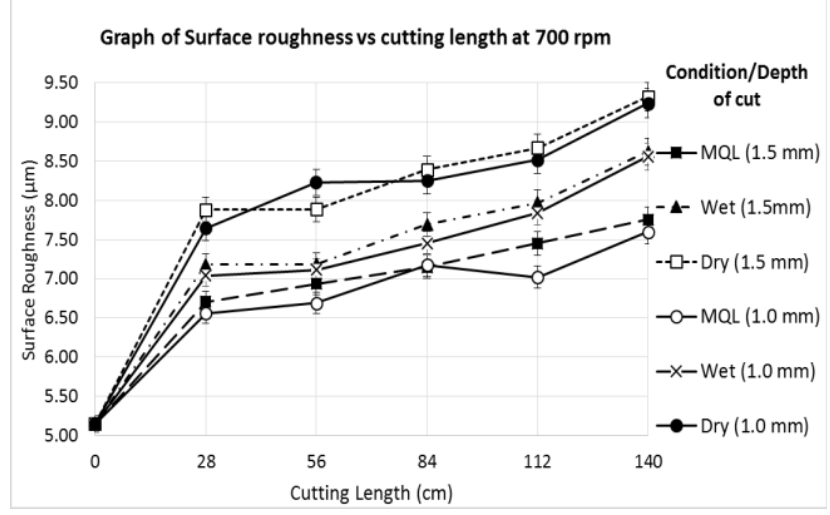

Figure 7. Graph of surface roughness against cutting length at $700 \mathrm{rpm}$.

The growth of notch wear with machining caused a change to the tool shape to a less flattened shape, which reduced the sharpness of the cutting edge (Figure 7). As the tool nose shape has a significant effect on cutting tool performance, hence there is a correlation between the tool notch wear and surface roughness values. It can be inferred that reduced notch and crater wear present under MQL condition also contributed to lower surface roughness values compared to the wet and dry conditions.

The results obtained from the ANOVA analysis (in Table - 2) for tool wear (principal flank wear) showed that the cutting environment $(60.66 \%)$ has the highest contribution to tool wear. Cutting speed $(26.11 \%)$ is the second most significant factor to tool wear and was followed by the depth of cut $(9.90 \%)$.
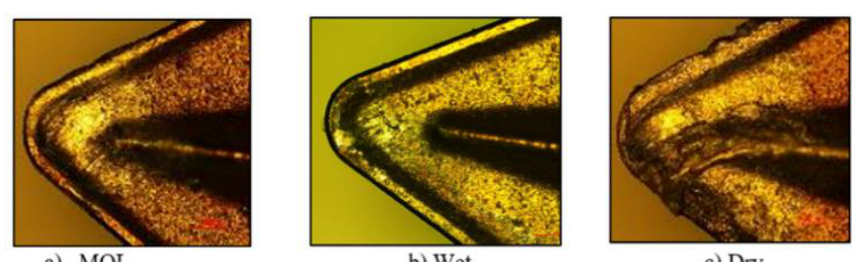

a) MQL

b) Wet

c) Dry

Figure 8. Comparison of tool rake face under same cutting parameters.

Table 2. ANOVA for tool wear.

\begin{tabular}{|l|l|l|l|l|l|l|}
\hline $\begin{array}{l}\mathbf{N} \\
\mathbf{0 .}\end{array}$ & Factor & $\begin{array}{l}\text { Degre } \\
\text { e of } \\
\text { Freed } \\
\text { om }\end{array}$ & $\begin{array}{l}\text { Sum } \\
\text { of } \\
\text { Squar } \\
\text { es }\end{array}$ & $\begin{array}{l}\text { Mean } \\
\text { Squar } \\
\text { es }\end{array}$ & $\begin{array}{l}\text { F- } \\
\text { Value }\end{array}$ & $\begin{array}{l}\text { Percent } \\
\text { age } \\
\text { Contrib } \\
\text { ution } \\
\text { (\%) }\end{array}$ \\
\hline $\mathbf{1}$ & $\begin{array}{l}\text { Environ } \\
\text { ment }\end{array}$ & 1 & $\begin{array}{l}29168 . \\
444\end{array}$ & $\begin{array}{l}29168 . \\
444\end{array}$ & $\begin{array}{l}72.735 \\
445\end{array}$ & 60.66 \\
\hline $\mathbf{2}$ & $\begin{array}{l}\text { Cutting } \\
\text { Speed }\end{array}$ & 2 & $\begin{array}{l}12553 . \\
469\end{array}$ & $\begin{array}{l}6276.7 \\
35\end{array}$ & $\begin{array}{l}15.651 \\
883\end{array}$ & 26.11 \\
\hline $\mathbf{3}$ & $\begin{array}{l}\text { Depth } \\
\text { of cut }\end{array}$ & 1 & $\begin{array}{l}4760.7 \\
21\end{array}$ & $\begin{array}{l}4760.7 \\
21\end{array}$ & $\begin{array}{l}11.871 \\
499\end{array}$ & 9.90 \\
\hline $\mathbf{4}$ & Error & 4 & $\begin{array}{l}1604.0 \\
84\end{array}$ & $\begin{array}{l}401.02 \\
1\end{array}$ & - & 3.34 \\
\hline $\mathbf{5}$ & Total & 8 & $\begin{array}{l}48086 . \\
718\end{array}$ & - & - & 100.00 \\
\hline
\end{tabular}

Cutting condition has a large influence on flank wear as MQL provides lubrication, cooling effect and chip flushing/breaking effect. Machining with MQL resulted in shorter tool-chip contact length, less work and chip material adhered on the rake face, lower cutting temperatures due to lower friction generated, lower cutting forces and less possibility for built up edge formation, which ultimately resulted in lower tool wear on the flank surfaces compared to dry condition. Cutting speed also affects the MQL effectiveness. At lower speeds, MQL lubricating ability is more essential while at higher speeds, MQL cooling properties are much more significant due to increased heat generated at higher speeds. As the cutting fluid used in this study was water soluble, hence at higher speeds, the MQL effectiveness should be greater due to increased vaporized liquid at higher speeds, which would reduce cutting temperatures involved and consequently lesser tool wear [19].

Table 3. ANOVA for surface roughness.

\begin{tabular}{|l|l|l|l|l|l|l|}
\hline $\begin{array}{l}\mathbf{N} \\
\mathbf{0 .}\end{array}$ & Factor & $\begin{array}{l}\text { Degr } \\
\text { ee of } \\
\text { Free } \\
\text { dom }\end{array}$ & $\begin{array}{l}\text { Sum } \\
\text { of } \\
\text { Squa } \\
\text { res }\end{array}$ & $\begin{array}{l}\text { Mea } \\
\mathbf{n} \\
\text { Squa } \\
\text { res }\end{array}$ & $\begin{array}{l}\text { F- } \\
\text { Value }\end{array}$ & $\begin{array}{l}\text { Percent } \\
\text { age } \\
\text { Contrib } \\
\text { ution } \\
\mathbf{( \% )}\end{array}$ \\
\hline $\mathbf{1}$ & $\begin{array}{l}\text { Environ } \\
\text { ment }\end{array}$ & 1 & $\begin{array}{l}3.07 \\
7\end{array}$ & $\begin{array}{l}3.07 \\
7\end{array}$ & $\begin{array}{l}204.2 \\
5174\end{array}$ & 67.64 \\
\hline $\mathbf{2}$ & $\begin{array}{l}\text { Cutting } \\
\text { Speed }\end{array}$ & 2 & $\begin{array}{l}1.09 \\
1\end{array}$ & $\begin{array}{l}0.54 \\
5\end{array}$ & $\begin{array}{l}36.19 \\
4951\end{array}$ & 23.97 \\
\hline $\mathbf{3}$ & $\begin{array}{l}\text { Depth } \\
\text { of cut }\end{array}$ & 1 & $\begin{array}{l}0.32 \\
1\end{array}$ & $\begin{array}{l}0.32 \\
1\end{array}$ & $\begin{array}{l}21.32 \\
1758\end{array}$ & 7.06 \\
\hline $\mathbf{4}$ & Error & 4 & $\begin{array}{l}0.06 \\
0\end{array}$ & $\begin{array}{l}0.01 \\
5\end{array}$ & - & 1.32 \\
\hline
\end{tabular}




\begin{tabular}{|l|l|l|l|l|l|l|}
\hline 5 & Total & 8 & $\begin{array}{l}4.54 \\
9\end{array}$ & - & - & 100.00 \\
\hline
\end{tabular}

The ANOVA analysis (in Table - 3) for surface roughness also described cutting environment (67.64 \%) as the highest contributor to surface roughness. The second most significant factor is the cutting speed $(23.97 \%)$ followed by depth of cut $(7.06 \%)$. Thus, cutting environment has the greatest influence in the surface roughness and tool wear parameter, with MQL providing improved tool wear and surface roughness values.

\section{Conclusion}

The MQL setup developed was successful in delivering a steady jet of air-oil lubrication at the cutting point. The minimum quantity lubrication (MQL) technique ensured lower surface roughness and tool wear (flank wear) values due to lower cutting temperatures, increased lubrication penetration and better chip flushing. Chips formed under MQL technique had decreased chip thickness compared to wet and dry conditions, due to reduced cutting temperature, improved chip-tool interaction and reduced built up edge (BUE) formation. Flank wear and notch wear were found to be influential to the surface roughness when machining. Besides that, MQL reduced the growth of principal flank wear and notch wear, resulting in lower auxiliary flank wear and lower surface roughness values compared to wet and dry conditions. The ANOVA results for tool wear and surface roughness revealed that cutting environment has the greatest influence on the tool wear and surface roughness parameters, with MQL providing improved tool wear and surface roughness values.

\section{References}

1. D. J. Paulo, P. S. Sreejith, and J. Silva. Materials and Manufacturing Processes, Vol.22 (2007), p. 45-50.

2. Y. K. Hwang, and C. M. Lee, Journal of Mechanical Science and Technology, Vol. 24, (2010) p.1669

3. M. Nouari, G. List, F. Girot, and D. Coupard. Wear, Vol.255, (2003), p.1359
4. M. M. A.Khan, M. A. H. Mithu, and N. R. Dhar. Journal of Materials Processing Technology (2009), Vol.209, p.5573

5. N. R. Dhar, M. Kamruzzaman, and M.Ahmed. Journal of Materials Processing Technology, Vol.172, (2006), p.299

6. P. Zoltán, and G. Csernák. Journal of Sound and Vibration, Vol. 332,(2013), p.2057

7. A.Sharman, R. C. Dewes, and D. K. Aspinwall. Journal of Materials Processing Technology, Vol.118, (2001), p.29

8. G. List, , M. Nouari, D. Géhin, S. Gomez, J. P. Manaud, Y. Le Petitcorps, and F. Girot. Wear Vol.259, (2005), p.1177

9. M. A. Xavior, and M. Adithan. Journal of Materials Processing Technology, Vol.209, (2009), p.900

10. S. Paul, N. R. Dhar, and A. B. Chattopadhyay. Journal of Materials Processing Technology, Vol.116, (2001) p.44

[1] P. S. Sreejith, Materials Letters, (2008) Vol.62, (2008), p. 276

[2] S. Hamed, S.P. Khanghah, and R. Teimouri. The International Journal of Advanced Manufacturing Technology, Vol.76,(2015), p.2099

11. N. G. Phafat, R. R. Deshmukh, S. D. Deshmukh, Applied Mechanics and Materials, Vol. 393, (2013), p. 240

12. H. Mohammadjafar, and B. Sadeghi, Journal of Cleaner Production, Vol.54, (2013), p.332

13. Y. Hiromi, T. Moriwaki, N. Ohmae, T. Nakai, T. Shibasaka, H. Kinoshita, M.Matsui, and M. Shimizu. JSME International Journal Series C Mechanical Systems, Machine Elements and Manufacturing, Vol.49, (2006), p.83

14. H. H. Shahabi, and M. M. Ratnam. The International Journal of Advanced Manufacturing Technology,(2009), Vol. 40, p.1148

15. K. Ihsan, M. Kasap, I. Ciftci, and U. Seker. Materials \& Design, Vol.25, (2004),p.303

16. D. G,Thakur, B Ramamoorthy, and L Vijayaraghavan. International Journal of Materials and Structural Integrity, Vol.5, (2011),p.1

17. V. S. Sharma, M. Dogra, and N. M. Suri. International Journal of Machine Tools and Manufacture, Vol.49 (2009), p.435 